\title{
INFLUÊNCIA DA ÉPOCA DE PODA E TIPOS DE POLINIZAÇÃO NO FLORESCIMENTO E FRUTIFICAÇÃO DA PINHA ${ }^{1}$
}

\author{
PAULO CESAR DOS SANTOS ${ }^{2}$, ABDON SANTOS NOGUEIRA ${ }^{3}$, \\ MARTA SIMONE MENDONÇA FREITAS ${ }^{4}$, JALILLE AMIM ALTOÉ FREITAS ${ }^{5}$, \\ ALMY JUNIOR CORDEIRO DE CARVALHO ${ }^{6}$
}

RESUMO- O desconhecimento de tecnologias, que permitam melhorias no manejo da cultura da pinha, principalmente no que se refere às épocas de podas e métodos de polinização, limita o crescimento da área plantada desta fruta no Brasil. Nesse sentido, o objetivo deste trabalho foi avaliar o desenvolvimento de frutos de pinha em função de épocas de poda e de métodos de polinização. O experimento foi conduzido no município de São Francisco do Itabapoana-RJ, no período compreendido entre abril de 2001 e fevereiro de 2002. O delineamento experimental adotado foi em blocos casualizados (DBC), com parcelas subdivididas, em esquema fatorial 5x3, sendo cinco épocas de poda (maio, junho, julho, agosto e setembro de 2001) e três métodos de polinização (Polinização aberta ou natural; Polinização com pincel macio, realizada diretamente na flor, e Polinização realizada com bomba polinizadora), com quatro repetições. O comprimento e o diâmetro dos ramos foram influenciados pela época de poda. Os dois métodos de polinização artificial aumentaram a porcentagem de fecundação de frutos. O florescimento foi influenciado pela época de poda. Em média, o pico de desenvolvimento dos frutos foi verificado com aproximadamente 50 dias após a polinização e foi superior quando se utilizou a polinização artificial.

Termos para indexação: Annona squamosa, fruta-do-conde, fruteiras.

\section{INFLUENCE OF PRUNING TIME AND POLLINATION TYPES IN FLOWERING AND FRUIT OF SUGAR APPLE}

\begin{abstract}
The lack of technologies that allow improvements in sugar-apple culture management, mainly regarding to pruning time and pollination methods, restricts the growth of the cultivated area with this fruit in Brazil. In this sense, the aim is of evaluating sugar-apple fruit development and growth on the basis of pruning time and pollination methods. The experiment was conducted in the city of São Francisco do Itabapoana-RJ, in the period from April 2001 to February 2002. The experimental design was randomized blocks design (RBD), with plots subdivided in $5 \times 3$ factorial scheme, being five times of pruning (May, June, July, August and September 2001) and three pollination methods (natural pollination; pollination with soft brush, held directly in flower and pollination with pump), with four replications. The length and diameter of the branches were influenced by the pruning season. Both artificial pollination methods increased the percentage of fruit fertilization. Flowering was influenced by pruning time. On average, the peak of fruit development was verified about 50 days after pollination and it was higher when artificial pollination was used.

Index terms: Annona squamosa, sugar-apple, fruit tree.
\end{abstract}

\footnotetext{
${ }^{1}$ (Trabalho 065-13) - Recebido em: 07-08-2013. Aceito para publicação em: 12-12-2013. V Congresso Internacional \& Encontro Brasileiro sobre Annonaceae: do gene à exportação (19 a 23 de Agosto de 2013). Botucatu-SP.

${ }^{2}$ Doutorando em Produção Vegetal, UENF/CCTA/LFIT, Campos-RJ. E-mail: pcsantos18@hotmail.com

${ }^{3}$ Professor de Ensino Tecnológico, EAFSI, Ubaíra Santa Inês-BA. E-mail: abdon.nogueira@si.ibaiano.edu.br

${ }^{4}$ Professora Associada de Nutrição Mineral, UENF/CCTA/LFIT, Campos-RJ. E-mail: msimone@uenf.br

${ }^{5}$ Pós-doutoranda, UENF/CCTA/LFIT, Campos-RJ. E-mail: jalilleamim@yahoo.com.br

${ }^{6}$ Professor de Fruticultura, UENF/CCTA/LFIT, Campos-RJ. E-mail: almy@uenf.br
} 


\section{INTRODUÇÃO}

Dentre as anonáceas mais cultivadas no mundo, pode-se destacar a pinha ou fruta-do-conde (Annona squamosa L.), como normalmente é conhecida. É originária da América Tropical, mais precisamente, nas terras baixas da América Central. Apresenta boas perspectivas econômicas de cultivo para diversas regiões do Brasil, devido à sua fácil adaptação edafoclimática, inclusive às condições existentes no Estado do Rio de Janeiro.

Por apresentar boa qualidade de frutos (GOUVEIA et al., 2006), além de satisfatória rentabilidade, esta espécie vem despertando o interesse dos fruticultores de várias partes do País, para o seu cultivo, pois além das propriedades alimentares, as anonáceas apresentam valor medicinal, propriedades farmacêuticas (SINGH, 2011; MADHU et al., 2011) e, ainda, potencial como inseticidas (SEFFRIN et al., 2010). Contudo, o desconhecimento de tecnologias que permitam melhorias no manejo da cultura, principalmente no que concerne à produção de mudas (SAMARÃO et al., 2011; COELHO et al., 2012), aos métodos de polinização (MOTA FILHO et al., 2012) e à qualidade de frutos (SOUZA et al., 2012; MIZOBUTSI et al., 2012), vem limitando a expansão da área plantada no Brasil, apesar do interesse dos produtores, atraídos pelos preços de mercado dessa fruta (COSTA et al., 2002).

A poda é uma técnica importante para o cultivo da pinheira, proporcionando a diferenciação floral de maneira a permitir frutificação fora de época. As respostas ao estímulo para a obtenção do novo ciclo são muito influenciadas pelas condições climáticas, necessitando de regionalização dos estudos (DIAS et al., 2003).

A prática de indução floral, através da poda de produção, aliada a outra técnica, como a polinização artificial, é indispensável para uniformizar a produção, obter maior pegamento e melhor qualidade dos frutos, além de incrementar a produtividade (MOTA FILHO et al., 2012), que, consequentemente, proporcionará maior remuneração ao produtor. Em pinheiras, quando ocorre boa polinização, os frutos desenvolvem-se normalmente, apresentando maior porcentagem de frutos formados e perfeitos, além de frutos com maior comprimento e diâmetro (CAMPOS et al., 2004).

$\mathrm{O}$ aumento da frutificação por meio da polinização artificial tem sido divulgado em trabalhos científicos em anonáceas (MOTA FILHO et al., 2012). No entanto, tornam-se necessários mais estudos regionalizados para otimizar e adaptar esta prática à realidade dos agricultores. Dessa maneira, $\mathrm{o}$ objetivo deste trabalho foi avaliar o desenvolvimento dos frutos de pinha em função das épocas de poda e das formas de polinização.

\section{MATERIAL E MÉTODOS}

$\mathrm{O}$ experimento foi conduzido numa propriedade rural, no município de São Francisco de Itabapoana-RJ, localizado nas coordenadas latitude $21^{\circ} 19^{\prime} 22^{\prime \prime}$ e longitude $41^{\circ} 07^{\prime} 42^{\prime \prime}$. A área cultivada com pinha obtida de pé-franco foi de um hectare, com cinco anos de idade e cultivada num solo tipo Argissolo Amarelo distrófico. Segundo a classificação climática de Köppen, o clima da região Norte Fluminense é classificado como Aw, clima tropical úmido, com verão chuvoso, inverno seco e temperatura do mês mais frio superior a $18^{\circ} \mathrm{C}$. Os dados climáticos do local durante o período de condução dos experimentos são apresentados na Tabela 1, e os resultados da análise de solo da área experimental, no início da implantação do experimento, estão descritos na Tabela 2.

$\mathrm{O}$ delineamento experimental adotado foi o em blocos casualizados (DBC), em esquema de parcelas subdivididas $5 \times 3$, sendo cinco épocas de poda (maio, junho, julho, agosto e setembro) e três métodos de polinização (Polinização aberta ou natural; Polinização com pincel macio, realizada diretamente na flor, e Polinização realizada com bomba polinizadora e com pólen colhido no dia anterior), com quatro repetições. As parcelas foram constituídas por 15 plantas, sendo avaliadas as três centrais. $\mathrm{O}$ espaçamento entre plantas foi de 4 x 4 metros.

Em março de 2001, foi realizada uma poda de limpeza. Após esta etapa, ocorreram as podas de produção, efetuadas mensalmente a partir do mês de maio até setembro de 2001, onde os ramos foram encurtados a um comprimento médio de $25 \mathrm{~cm}$. Além da poda, foi realizada manualmente a desfolha dos ramos, iniciando-se da extremidade para sua base, para estimular o desenvolvimento vegetativo das gemas localizadas nas axilas das folhas. Após a poda dos ramos, foram marcados 12 ramos por planta, perfazendo um total de 36 ramos por parcela, para posterior avaliação.

Antes da instalação do experimento, todas as plantas receberam uma aplicação de $750 \mathrm{~g}$ de calcário por planta e adubação de cobertura, com base na análise de solo (Tabela 2).

Após a poda das plantas, em suas respectivas épocas, foi realizada uma adubação com $40 \mathrm{~g}$ de nitrogênio e $10 \mathrm{~g}$ de ácido bórico, sendo suplementada com $30 \mathrm{~g}$ de $\mathrm{P}_{2} \mathrm{O}_{5}$ a partir do segundo mês. Além 
disso, cada planta recebeu $100 \mathrm{~g}$ de $\mathrm{K}_{2} \mathrm{O}$, durante o período da frutificação. A irrigação foi fornecida por microaspersão, sendo um microaspersor por planta.

Para a extração do pólen, foram coletadas flores em estádio masculino, as quais foram acondicionadas sob refrigeração $\left(20^{\circ} \mathrm{C}\right)$, em bandejas plásticas, para manterem-se viáveis até o dia seguinte, no momento da polinização. O horário de coleta das flores foi ao final da tarde, por volta das 18 horas. Passado este período de armazenamento, as flores foram retiradas da geladeira, colocadas em peneira de malha de $1 \mathrm{~mm}$, para separação de pétalas e outros vestígios florais. Em seguida, os grãos de pólen foram utilizados para a polinização de flores que se encontravam receptivas em estádio feminino, no campo.

O período estabelecido para a realização da polinização nas condições da região foi entre as 6 horas e 9 horas e 30 minutos do período matutino, pois, a partir desse horário, as flores já se encontravam pouco receptivas, com queda dos grãos de pólen em decorrência de ventos, além do ressecamento do estigma.

A polinização artificial foi realizada em 15 flores por planta, totalizando 45 flores por tratamento, em cada parcela. Este processo foi distribuído por toda a copa da planta. Para a polinização com pincel, foi utilizado um pincel com pelos de seda e superfície plana e, através de movimentos circulares leves, realizou-se a polinização, diretamente em flores com o estigma receptivo. Para a polinização com bomba polinizadora, os grãos de pólen foram colocados dentro da câmara de pólen da bomba de polinização artificial e, em seguida, efetuou-se a polinização, direcionando o bico do tubo polinizador no estigma floral, recoberto com uma camada mucilaginosa e brilhante. Para a polinização natural, marcou-se o mesmo número de flores, da mesma forma que nas polinizações artificiais. Tanto a polinização artificial como a natural foram realizadas no mesmo dia.

As características de desenvolvimento das plantas foram mensuradas por meio de avaliações referentes ao comprimento dos ramos (medidos quinzenalmente, em 12 ramos/planta, até 90 dias após a realização da poda), diâmetro dos ramos (medido quinzenalmente, em 12 ramos/planta, até 90 dias após a realização da poda, na porção mediana, utilizando um paquímetro digital) e o número de dias entre a poda e o início do florescimento (definido a partir da emissão da primeira flor).

No florescimento e na frutificação, as plantas foram avaliadas quanto ao número de flores por ramo (a partir do florescimento, a cada 15 dias, e o número de flores/ramo foi obtido a partir da média de flores de 12 ramos previamente marcados), número de frutinhos por ramo (15 dias após a polinização, para determinar a fecundação de flores e o desenvolvimento dos frutos) e quanto ao diâmetro e ao comprimento dos frutos até 60 dias após a polinização (medidos a cada 15 dias depois de ocorrida a polinização).

Os dados foram submetidos a análises de variância pelo teste $\mathrm{F}$, as médias obtidas para época de poda foram submetidas a análises de regressão (5\% de probabilidade), enquanto as médias obtidas para época de poda e formas de polinização foram comparadas pelo teste de Tukey $(5 \%$ de probabilidade).

\section{RESULTADOS E DISCUSSÃO}

O crescimento dos ramos foi diferenciado em função das diferentes épocas de poda. Para o comprimento e o diâmetro dos ramos, observou-se que a primeira época de poda proporcionou brotações tardias das plantas (Figuras 1A e 1B), além de morte ou ausência de brotação, provavelmente acarretada pelas condições climáticas deste período (Tabela 1). Foi observado, também, nesta primeira época, redução no desenvolvimento vegetativo das plantas, com pequeno fluxo de florescimento (Figura 2), embora tenha ocorrido frutificação. Contrastando com a poda efetuada em maio, aquelas realizadas nos meses de agosto e setembro proporcionaram maior comprimento e diâmetro dos ramos (Figuras 1A e 1B).

Para as condições edafoclimáticas do município de São Francisco do Itabapoana, verificouse que a pinha pode florescer praticamente durante todo o ano, porém há uma variação na intensidade de florescimento ao longo dos meses do ano, como verificado no período compreendido entre a poda e o florescimento, apresentada na Figura 2. Na cultura da goiabeira, Hojo et al. (2007) observaram a produção de frutos de boa qualidade ao longo de nove meses do ano, com o manejo das podas.

A partir de maio, foi verificado que grande parte das folhas das plantas perdeu a coloração verde-intensa, passando a verde-clara, ocorrendo nos meses seguintes, junho e julho, queda parcial destas folhas. Em agosto, a planta começou a emissão de novas folhas, e até o final do mês de outubro, elas se encontravam em pleno vigor vegetativo.

Durante o período de queda de folhas senescentes e a formação de novas folhas, as plantas produziram um reduzido número de flores, com exceção ao mês de setembro, em que ocorreu o máximo de floração, 15 dias após a poda de produção 
(Figura 2 e Tabela 3).

Para a primeira época de poda, o florescimento foi praticamente nulo, até aos 45 dias após a poda de produção (Tabela 3), tendo-se um incremento crescente, no número de flores por ramo, a partir desta data (Figura 2). Na segunda época de poda, o máximo de florescimento, com 21 flores por ramo, ocorreu aos 86 dias após a poda de produção (Figura 2). Nas podas realizadas nos meses de julho e agosto, o máximo florescimento foi verificado aos 51 e 45 dias, respectivamente, com um total de 25 flores por ramo para os dois períodos de poda de produção. $\mathrm{O}$ número de flores na última época de poda foi maior, quando comparado com as demais. Este fato pode ser explicado pelas condições climáticas verificadas nesta época, que o máximo de florescimento foi aos 15 dias após a poda (Figura 2).

$\mathrm{O}$ pequeno número de flores observado para a primeira época de poda pode ser explicado pelo pequeno número de brotações e, principalmente, pelo menor crescimento dos ramos, após a poda, o que sugere que as plantas tendem a um crescimento vegetativo em detrimento da produção.

Durante o monitoramento do desenvolvimento das flores fecundadas e dos frutos, observou-se a identificação de três fases distintas nesta cultura, sendo a primeira fase caracterizada pelo crescimento lento do botão floral, com a presença de pétalas semiabertas. Antes da completa abertura das flores, tanto as pétalas exteriores como as interiores caíam ao solo e, nesse momento, iniciava-se o desprendimento dos estames junto ao receptáculo, com abertura das anteras e liberação dos grãos de pólen.

Em alguns casos, a receptividade estigmática (presença de secreção brilhante e viscosa sobre o estigma) permaneceu durante a fase de desprendimento dos estames, com a liberação dos grãos de pólen, favorecendo com isso a autopolinização das flores.

A porcentagem de fecundação de flores em função do método de polinização está apresentada na Figura 3. Pelos resultados obtidos neste trabalho, verificou-se que a utilização da bomba polinizadora proporcionou maior fecundação das flores $(94,9 \%)$ em relação às outras formas de polinização, atingindo fecundação de 7,6\% e 87,6\%, para os métodos de polinização natural e com pincel, respectivamente. Essa baixa porcentagem de pegamento de flores pelo método natural de polinização é explicada pela diferença nas fases de amadurecimento das estruturas reprodutivas (dicogamia protogínica) que ocorre na cultura da pinha (KISHORE et al., 2012). Resultados similares também foram encontrados por Kumaret et al. (1977), que, em condições ótimas de clima, obtiveram um índice de $8 \%$ para o pegamento de flores e por Campos et al. (2004), que obtiveram $10 \%$ de frutos de pinha formados. Em atemoieira, Mota Filho et al. (2012) verificaram eficiência do uso de polinização artificial, obtendo elevado índice de pegamento de frutos $(75 \%)$.

Observa-se que os frutos polinizados, nas diferentes épocas de poda, apresentaram um desenvolvimento diferenciado entre os métodos de polinização (Tabela 4 e Figura 4A). O menor diâmetro foi obtido quando a poda foi realizada em maio, com $16,8 \mathrm{~mm}$, por meio da polinização natural. Nos meses de junho e setembro, não foi verificado diferença entre os métodos de polinização (Tabela 4).

Os maiores valores de comprimento e diâmetro dos frutos estão relacionados em função dos dias após a polinização, ou seja, os frutos apresentaram uniformidade (Figuras 4A e 4B). Considerando-se as épocas de poda e o período após a polinização das flores, verificou-se que os frutos atingiram o maior diâmetro aos 55 dias após a polinização para o mês de agosto, 51 dias para setembro, 54 dias para julho, 52 dias para junho e 54 dias para maio (Figura 4A).

Em relação ao comprimento do fruto, observou-se que, para a poda da época de maio, o fruto levou 58 dias após a polinização para atingir seu comprimento máximo. Por outro lado, quando consideramos o último mês de poda (setembro), os frutos levaram 51 dias após a polinização para atingir seu máximo desenvolvimento (Figura 4B).

Os métodos de polinização artificial (pincel e bomba polinizadora) proporcionaram maior comprimento dos frutos, independentemente da época de poda, exceto a polinização natural para a época de junho. Nos meses de maio, julho e agosto, o comprimento do fruto foi menor quando foi realizada a polinização natural (Tabela 5).

Os métodos de polinização artificial proporcionaram maior desenvolvimento dos frutos em relação aos obtidos com a polinização natural (Figuras 5A e 5B). Por meio de estimativas, foi verificado que o máximo de comprimento dos frutos foi de 40,7; 68,9 e $67,7 \mathrm{~mm}$, para os tratamentos com polinização natural, polinização com pincel e polinização com bomba polinizadora, aos 51;55 e 54 dias após a polinização, respectivamente. Resultados semelhantes foram encontrados para o diâmetro dos frutos (Figura 5B).

A polinização realizada de forma ineficiente é um fator que limita a produção da pinheira. Campos et al. (2004) concluíram que o uso da polinização artificial, com pincel ou com bomba polinizadora, aumenta em até 10 vezes o número 
de frutos formados e em até 4 vezes o número de frutos perfeitos, quando comparada à polinização natural livre feita por insetos. Além disso, os autores observaram que a utilização da polinização com pincel e bomba polinizadora proporcionou incrementos de $153 \%$ e $52 \%$ para comprimento e diâmetro dos frutos de pinha, respectivamente, em relação ao método de polinização natural.
Os resultados obtidos neste trabalho, referentes ao comprimento e ao diâmetro dos frutos aos 45 dias após a polinização (Figuras 5A e 5B), foram superiores aos encontrados por Campos et al. (2004), utilizando os mesmos métodos artificiais de polinização. Já aos 60 dias após a polinização artificial, foram próximos aos encontrados por Dias et al. (2003) e Araújo et al. (2008).

TABELA 1- Características climáticas observada no ano de 2001 em pomar de pinha localizado no município de São Francisco de Itabapoana-RJ

\begin{tabular}{|c|c|c|c|c|c|c|c|c|c|}
\hline \multirow{2}{*}{ Mês } & \multicolumn{2}{|c|}{$\begin{array}{c}\text { Temp. média } \\
\left({ }^{\circ} \mathrm{C}\right)\end{array}$} & \multicolumn{2}{|c|}{$\begin{array}{l}\text { Precipitação } \\
\left(\mathrm{mm} \text { mês }^{-1}\right)\end{array}$} & \multicolumn{2}{|c|}{$\begin{array}{c}\text { Umid. Relativa } \\
(\%)\end{array}$} & \multicolumn{2}{|c|}{$\begin{array}{c}\mathrm{ET}_{\mathrm{o}}^{3} \\
\left(\mathrm{~mm} \mathrm{dia}^{-1}\right)\end{array}$} & \multirow[t]{2}{*}{$\begin{array}{c}\text { Luz } \\
\left(\text { horas } \operatorname{dia}^{-1}\right) \\
\end{array}$} \\
\hline & $\mathrm{A}^{1}$ & $\mathrm{~B}^{2}$ & $\mathrm{~A}^{1}$ & $\mathrm{~B}^{2}$ & $\mathrm{~A}^{1}$ & $\mathrm{~B}^{2}$ & $\mathrm{~A}^{1}$ & $\mathrm{~B}^{2}$ & \\
\hline Janeiro & 27,1 & 26,8 & 119 & 50,3 & 76,5 & 75,7 & 5,10 & 4,70 & 13,3 \\
\hline Fevereiro & 27,6 & 28,1 & 77 & 21,7 & 74,3 & 73,6 & 5,35 & 5,76 & 12,8 \\
\hline Março & 26,2 & 27,4 & 85 & 31,9 & 76,3 & 75,4 & 5,50 & 4,86 & 12,2 \\
\hline Abril & 24,2 & 26,0 & 78 & 48,3 & 77,7 & 76,4 & 3,70 & 4,25 & 11,6 \\
\hline Maio & 22,4 & 23,2 & 51 & 54,1 & 77,2 & 77,0 & 3,10 & 2,95 & 11,2 \\
\hline Junho & 21,3 & 22,5 & 30 & 12,8 & 77,3 & 78,2 & 2,60 & 2,57 & 10,8 \\
\hline Julho & 21,4 & 21,7 & 34 & 4,9 & 74,8 & 76,5 & 2,80 & 2,77 & 10,9 \\
\hline Agosto & 22,2 & 21,7 & 29 & 0,2 & 76,4 & 76,9 & 3,40 & 3,18 & 11,3 \\
\hline Setembro & 22,9 & 22,1 & 56 & 30,4 & 78,0 & 75,8 & 3,70 & 3,40 & 12,0 \\
\hline Outubro & 24,0 & 22,5 & 96 & 74,2 & 78,1 & 78,5 & 4,00 & 3,99 & 12,6 \\
\hline Novembro & 25,1 & 24,7 & 155 & 118,3 & 78,8 & 83,1 & 4,50 & 4,15 & 13,2 \\
\hline Dezembro & 25,5 & 25,7 & 166 & 209,8 & 76,3 & 78,6 & 4,70 & 4,83 & 13,4 \\
\hline MÉDIA & 24,2 & 24,4 & 81 & 54,7 & 76,8 & 77,2 & 4,03 & 3,95 & 12,1 \\
\hline
\end{tabular}

$\mathrm{A}^{1}=$ média de 21 anos $(1979-2000) . \mathrm{B}^{2}=$ média em 2001. $\mathrm{ET}_{\mathrm{o}}{ }^{3}$ obtida a partir da Evaporação do Tanque Classe $\mathrm{A}\left(\mathrm{ET} \mathrm{T}_{\mathrm{o}}=\mathrm{Kt} * \mathrm{EV}\right) \mathrm{e}$ (Penman - Monteith).

Fonte: Universidade Federal Rural do Rio de Janeiro, Câmpus Leonel Miranda e Estação Evapotranspirométrica - Convênio UENF/ Pesagro-Rio.

TABELA 2- Análise química de amostra de solo (camada de 0 a $20 \mathrm{~cm}$ ) do pomar de pinha localizado no município de São Francisco de Itabapoana - RJ, na ocasião da implantação do experimento

\begin{tabular}{|c|c|c|c|c|c|c|c|c|c|c|c|c|}
\hline $\mathrm{pH}$ & K & $\mathrm{Ca}$ & $\mathrm{Mg}$ & & SB & $\mathrm{V}$ & $\mathrm{P}$ & $\mathrm{Fe}$ & $\mathrm{Cu}$ & $\mathrm{Zn}$ & $\mathrm{Mn}$ & B \\
\hline \multirow{2}{*}{6,3} & \multicolumn{5}{|c|}{$\mathrm{mmol}_{\mathrm{c}} \mathrm{dm}^{-3}$} & $(\%)$ & \multicolumn{6}{|c|}{$\mathrm{mg} \mathrm{dm} \mathrm{m}^{-3}$} \\
\hline & 0,55 & 1,91 & 0,32 & 0 & 2,96 & 64 & 62,0 & 24,58 & 0,63 & 10,45 & 52,76 & 0,88 \\
\hline
\end{tabular}

Laboratório de Análises de Solo da UFRRJ, Campos dos Goytacazes - --RJ. 
TABELA 3- Efeito da época de poda (maio, junho, julho, agosto e setembro de 2001) no número de flores por ramo da pinheira avaliado até aos 90 dias após a poda, em pomar de pinha com cinco anos de idade, localizado no município de São Francisco do Itabapoana-RJ

\begin{tabular}{|c|c|c|c|c|c|c|c|}
\hline \multirow{2}{*}{ Época de Poda } & \multicolumn{7}{|c|}{ Dias Após a Poda } \\
\hline & 15 & 30 & 45 & 60 & 75 & 90 & Média \\
\hline Maio & $\begin{array}{ll}0 & b\end{array}$ & $0 \mathrm{~d}$ & $0,2 \mathrm{c}$ & $3,4 \mathrm{c}$ & $18,3 \mathrm{a}$ & $29,6 \mathrm{a}$ & 8,6 \\
\hline Junho & & $0 \mathrm{~d}$ & $15,3 \mathrm{~b}$ & $15,3 \mathrm{a}$ & $26,3 \mathrm{a}$ & $17,5 \mathrm{~b}$ & 12,4 \\
\hline Julho & $0 \mathrm{~b}$ & $15,6 \mathrm{c}$ & $33,2 \mathrm{a}$ & $21,2 \mathrm{a}$ & $6,9 \mathrm{~b}$ & $0,7 \mathrm{c}$ & 13,0 \\
\hline Agosto & $0 \mathrm{~b}$ & $38,6 \mathrm{~b}$ & $27,7 \mathrm{a}$ & $13,1 \mathrm{ab}$ & $3,3 \mathrm{~b}$ & $0 \quad \mathrm{c}$ & 13,4 \\
\hline Setembro & $56,1 \mathrm{a}$ & $50,2 \mathrm{a}$ & $14,6 \mathrm{~b}$ & $5,0 \mathrm{bc}$ & $0,1 \mathrm{~b}$ & $0 \quad \mathrm{c}$ & 21,0 \\
\hline Média & 11,2 & 20,9 & 18,2 & 11,6 & 11,0 & 9,6 & 13,7 \\
\hline CV (\%) & & & & & & & \\
\hline
\end{tabular}

Médias seguidas pela mesma letra minúscula na linha não diferem entre si, pelo teste de Tukey, a 5\% de probabilidade.

TABELA 4- Diâmetro (mm) de frutos de pinha avaliados aos 60 dias após a polinização, em função das diferentes épocas de poda (maio, junho, julho, agosto e setembro de 2001) e métodos de polinização (polinização natural, polinização com pincel e com polinização com bomba polinizadora), em pomar de pinha com cinco anos de idade, localizado no município de São Francisco do Itabapoana-RJ

\begin{tabular}{lcccc}
\hline \multirow{2}{*}{ Época de Poda a } & \multicolumn{5}{c}{ Métodos de Polinização } \\
\cline { 2 - 5 } & Natural & Pincel & Bomba polinizadora & Média \\
\hline Maio & 16,8 b C & 43,0 a C & 51,0 a A & 36,9 \\
Junho & 56,7 a A & 51,5 a AB & 47,7 a A & 52,9 \\
Julho & 17,8 b C & 48,0 a BC & 52,9 a A & 39,5 \\
Agosto & 20,1 b C & 55,2 a A & 48,9 a A & 41,4 \\
Setembro & 38,3 a B & 52,6 a AB & 50,9 a A & 47,3 \\
\hline Média & 29,9 & 50,0 & 50,3 & 43,6 \\
\hline CV $(\%)^{*}$ & \multicolumn{5}{c}{5,94} \\
\hline CV $(\%)^{* *}$
\end{tabular}

Médias seguidas pela mesma letra, minúscula na linha e maiúscula na coluna, não diferem entre si, pelo teste de Tukey, a 5\% de probabilidade.

* Coeficiente de variação da parcela.

** Coeficiente de variação da subparcela.

TABELA 5- Comprimento ( $\mathrm{mm})$ de frutos de pinha avaliados aos 60 dias após a polinização, em função das diferentes épocas de poda (maio, junho, julho, agosto e setembro de 2001) e métodos de polinização (polinização natural, polinização com pincel e com polinização com bomba polinizadora), em pomar de pinha com cinco anos de idade, localizado no município de São Francisco do Itabapoana-RJ.

\begin{tabular}{lcccc}
\hline \multirow{2}{*}{ Época de poda } & \multicolumn{4}{c}{ Métodos de Polinização } \\
\cline { 2 - 5 } & Natural & Pincel & Bomba Polinizadora & Média \\
\hline Maio & 15,7 b C & 44,3 a A & 46,1 a A & 35,4 \\
Junho & 53,0 a A & 45,1 a A & 44,6 a A & 47,6 \\
Julho & 19,9 b C & 45,7 a A & 48,9 a A & 38,2 \\
Agosto & 20,8 b C & 49,1 a A & 47,8 a A & 39,2 \\
Setembro & 34,4 b B & 51,3 a A & 50,5 a A & 45,4 \\
\hline Média & 28,8 & 47,1 & 47,6 & 41,1 \\
\hline CV $(\%)^{*}$ & \multicolumn{5}{c}{19,8} \\
\hline CV $(\%)^{* *}$ & \multicolumn{5}{c}{4,30} \\
\hline
\end{tabular}

Médias seguidas pela mesma letra, minúscula na linha e maiúscula na coluna, não diferem entre si, pelo teste de Tukey, a $5 \%$ de probabilidade.

* Coeficiente de variação da parcela.

** Coeficiente de variação da subparcela. 

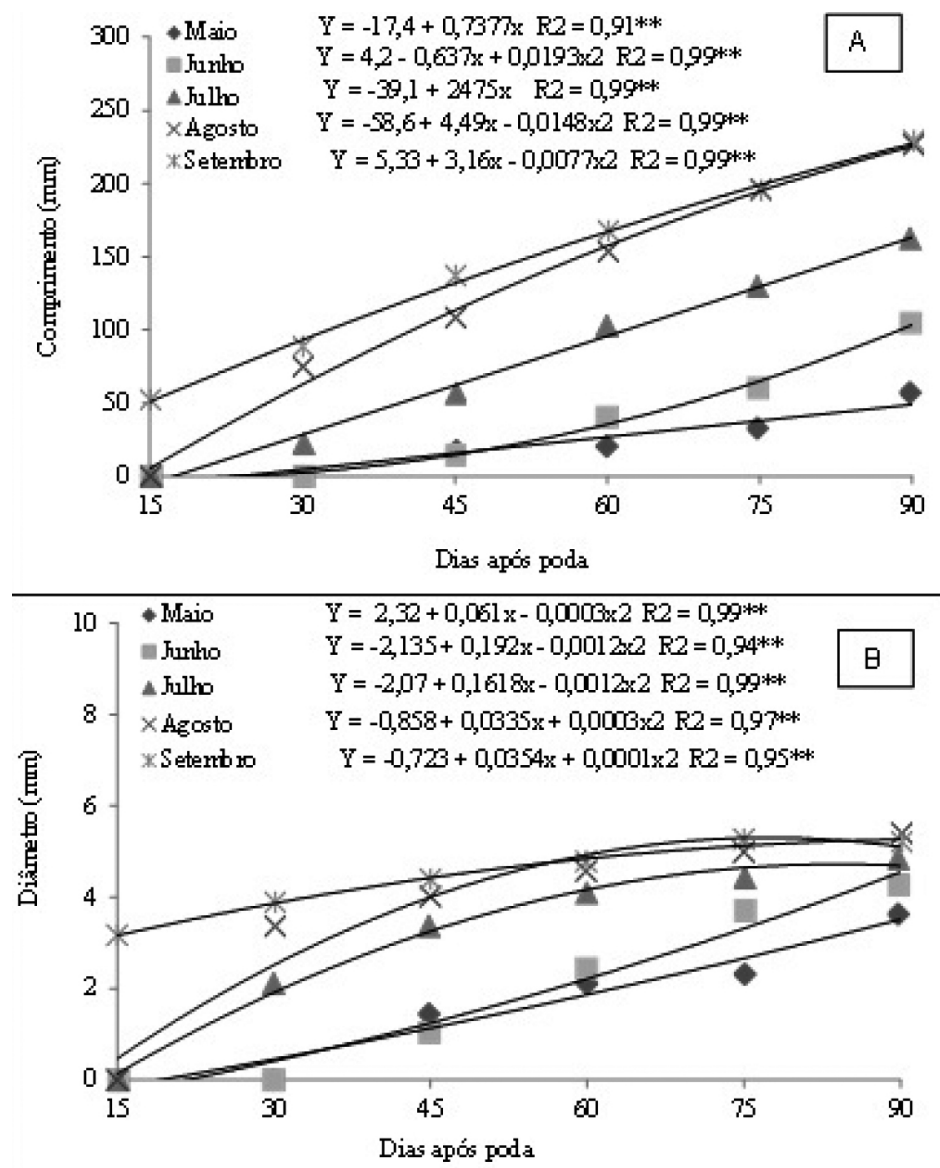

FIGURA 1- Efeito da época de poda (maio, junho, julho, agosto e setembro de 2001) no comprimento (A) e no diâmetro (B) do ramo da pinheira, em função de dias após a poda, em pomar de pinha com cinco anos de idade, localizado no município de São Francisco do Itabapoana-RJ.

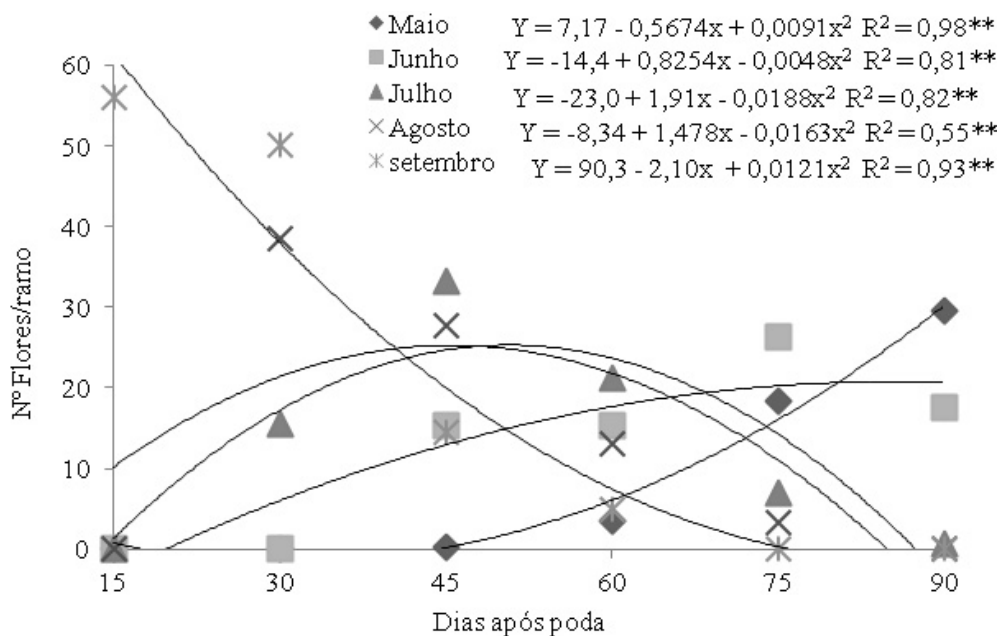

FIGURA 2- Efeito da época de poda (maio, junho, julho, agosto e setembro de 2001) no número de flores por ramo da pinheira, em função de dias após a poda, em pomar de pinha com cinco anos de idade, localizado no município de São Francisco do Itabapoana-RJ. 


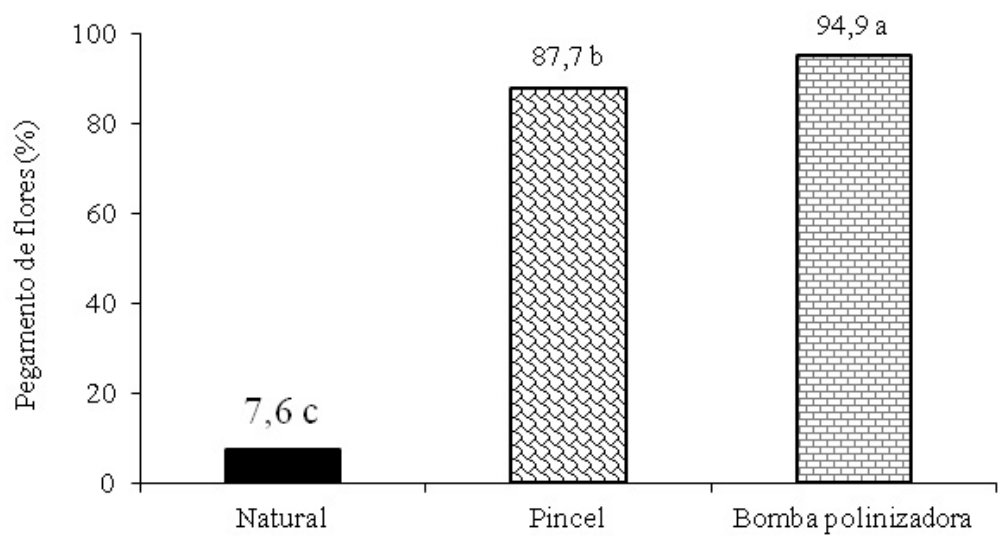

Método de Polinização

Médias seguidas pela mesma letra não diferem entre si, pelo teste de Tukey, a 5\% de probabilidade. CV = 4,68\%

FIGURA 3- Pegamento de flores em função do método de polinização (polinização natural, polinização com pincel e com polinização com bomba polinizadora), em pomar de pinha com cinco anos de idade, localizado no município de São Francisco do Itabapoana-RJ.
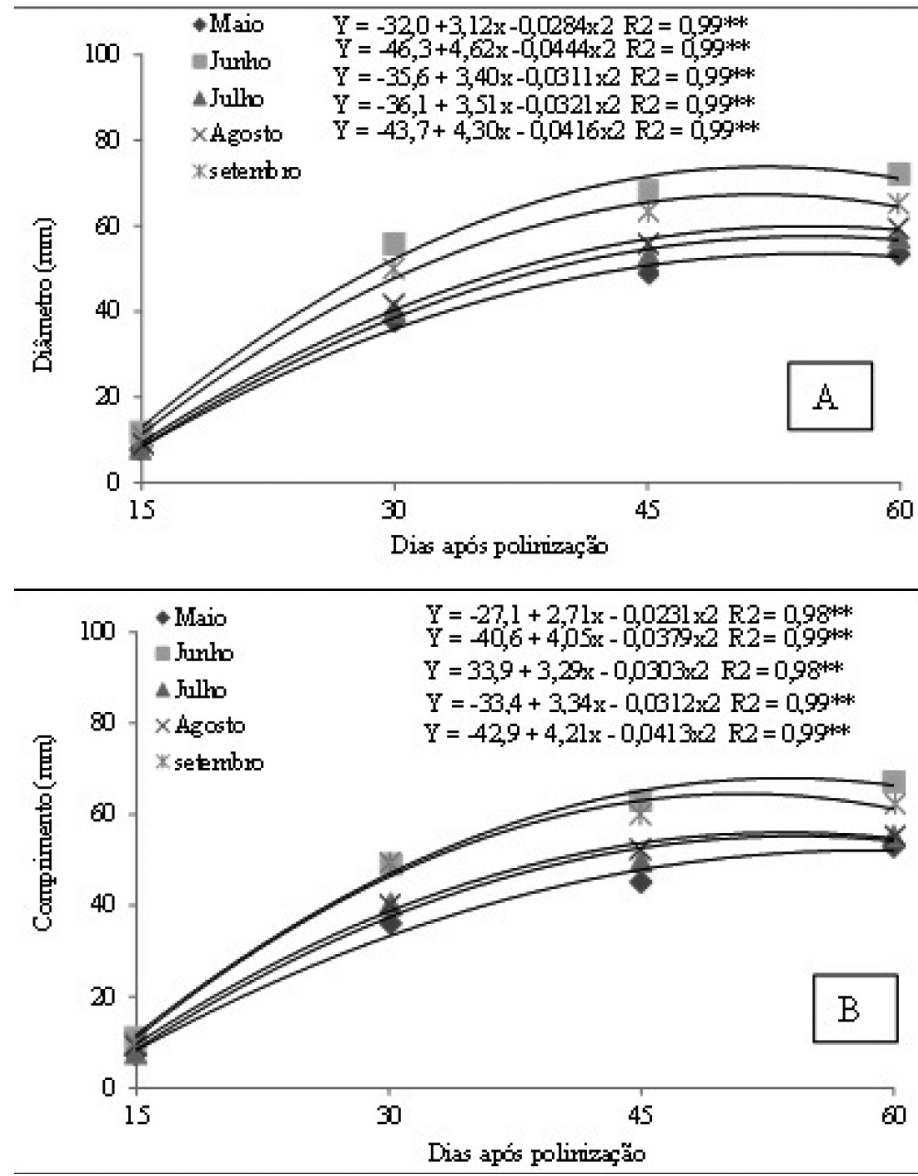

FIGURA 4-Efeito da época de poda (maio, junho, julho, agosto e setembro de 2001) no diâmetro (A) e comprimento (B) do fruto de pinha, em função dos dias após a polinização, em pomar de pinha com cinco anos de idade, localizado no município de São Francisco do Itabapoana-RJ. 

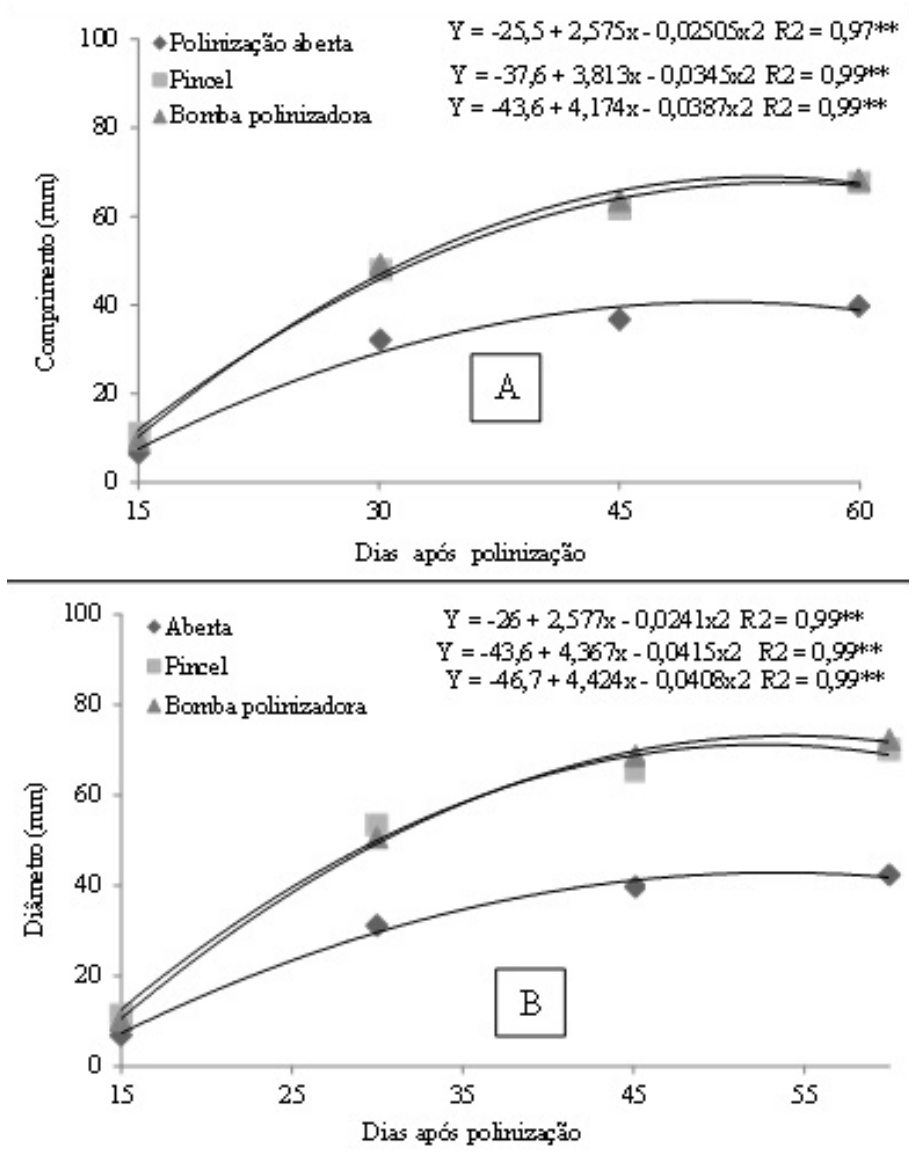

FIGURA 5- Comprimento (A) e diâmetro (B) dos frutos de pinha em função do método de polinização (polinização natural, polinização com pincel e com polinização com bomba polinizadora), em pomar de pinha com cinco anos de idade, localizado no município de São Francisco do Itabapoana-RJ.

\section{CONCLUSÕES}

1-As podas realizadas em maio e setembro proporcionam maior e menor intervalo entre a poda e o início do florescimento, respectivamente.

2-A polinização artificial aumenta a porcentagem de fecundação e o crescimento dos frutos.

\section{REFERÊNCIAS}

ARAÚJO, J. F.; LEONEL, S.; PEREIRA NETO, J. Adubação organomineral e biofertilização líquida na produção de frutos de pinheira (Annona squamosa L.), no submédio São Francisco, Brasil. Bioscience Journal, Uberlândia, v.24, n.4, p.48-57, 2008.
CAMPOS, R. da S.; EURICO, E. P. de L.; OLIVEIRA, J. F. de; FONSECA, F. K. P. da; SANTIAGO, A. D.; BARROS, P. G. Polinização natural, manual e autopolinização no pegamento de frutos de pinheira (Annona squamosa L.) em Alagoas. Revista Brasileira de Fruticultura, Jaboticabal, v.26, n.2, p.261-263, 2004.

COELHO, I. da R.; CAVACANTE, U. M. T.; CAMPOS, M. A. da S.; SILVA, F. S. B. Uso de fungos micorrízicos arbusculares (FMA) na promoção do crescimento de mudas de pinheira (Annona squamosa L.). Acta Botanica Brasilica, Feira de Santana, v. 26, n.4, p.933-937, 2012. 
COSTA, S. L.; CARVALHO, A. J.; PESSANHA, P. G. O.; MONNERAT, P. H.; MARINHO, C. S. Produtividade da cultura da Pinha (Annona squamosa L.) em função de níveis de adubação nitrogenada e formas de aplicação de boro. Revista Brasileira de Fruticultura, Jaboticabal, v.24, n.2, p.543-546, 2002 .

DIAS, N. O.; MATSUMOTO, S. N.; HOJO, T. N. R.; VIANA, A. E. S.; SÃO JOSÉ, A. R.; SOUZA, I. V. B. Influência da poda de produção em ramos de diferentes diâmetros no desenvolvimento vegetativo e reprodutivo da pinheira (Annona squamosa L.). Revista Brasileira de Fruticultura, Jaboticabal, v.25, n.1, p.100-103, 2003.

GOUVEIA, D. S.; MATA, M. E. R. M. C.; DUARTE, M. E. M.; UGULINO, S. M. P. Avaliação físicoquímica e teste de aceitação sensorial do suco de pinha e do blend pinha-leite. Revista Brasileira de Produtos Agroindustriais, Campina Grande, v.8, n.2, p.127-133, 2006.

HOJO, R. H.; CHALFUN, N. N. J.; HOJO, E. T. D.; VEIGA, R. D.; PAGLIS, C. M.; LIMA, L. C. de O. Produção e qualidade dos frutos da goiabeira 'Pedro Sato' submetida a diferentes épocas de poda. Pesquisa Agropecuária Brasileira, Brasília, v.42, n.3, p.357-362, 2007.

KISHORE, K.; SHUKLA, A. K.; BABU, N.; SARANGI, D. N.; PATANAYAK, S. Pollination biology of Annona squamosa L. (Annonaceae): Evidence for pollination syndrome. Scientia Horticulturae, Amsterdam, v.144, n.6, p.212-217, 2012.

KUMAR, R.; HODA, M. N.; SINGH, D. K. Studies on the floral biology of custard apple (Annona squamosa Linn), Indian journal of horticulture, Indian, v.34, n.3, p.252-256, 1977.

MADHU, CH.; BRAINARD, J. P.; RAJ, P. G.; SWAPN, J.; RAO, S. S. Anti ulcer activity of aqueous extract of Annona squamosa leaves on rats. International Journal of Pharmaceutical Sciences and Research, Jhansi, v.3, n.11, p.4.429-4.433, 2012.
MIZOBUTSI, G. P.; SILVA, J. M. da; MIZOBUTSI, E. H.; RODRIGUES, M. L. M.; LOPES, R. S.; FERNANDES, M. B.; OLIVEIRA, F. S. Conservação de pinha com uso de atmosfera modificada e refrigeração. Revista Ceres, Viçosa, MG, v.59, n.6, p.751-757, 2012.

MOTA FILHO, V. J.; GONÇALVES, M. C. T. P.; NIETSCHE, S.; GUIMARÃES, J. F. R.; MOREIRA, G. B. R.; FERNANDES, T. P. Uso de fitorreguladores no desenvolvimento de frutos na atemoieira (Annona cherimola x A. squamosa cv. Gefner). Revista Ceres,Viçosa, MG, v.59, n.5, p. 636-645, 2012.

SAMARÃO, S. S.; RODRIGUES, L. A.; MARTINS, M. A.; MANHÃES, T. N.; ALVIM, L. A. da M. Desempenho de mudas de gravioleira inoculadas com fungos micorrízicos arbusculares em solo não esterilizado, com diferentes doses de fósforo. Acta Scientiarum Agronomy, Maringá, v.33, n.1, p.81$88,2011$.

SEFFRIN, R. de C.; SHIKANO, I.; AKHTAR, Y.; ISMAN, M. B. Effects of crude seed extracts of Annona atemoya and Annona squamosa L. against the cabbage looper, Trichoplusiani in the laboratory and greenhouse. Crop Protection, Guildford, v.29, n.1, p.20-24, 2010.

SINGH, S. Pharmacological screening of combined extract of Annona squamosa and Nigella sativa. International Journal of Pharma and Bio Sciences, South Jordan, v.2, n.2, p.520-529, 2011.

SOUZA, I. V. B.; SÃO JOSÉ, A. R.; REBOUÇAS, T. N. H.; PIRES, M. de M.; MORAIS, O. M.; VIANA, A. E. S.; DIAS, N. O.; BOMFIM, M. P. Efeito do desbaste de frutos na produção e comercialização da pinha (Annona squamosa L.). Magistra, Cruz das Almas, v.24, n.2, p.89-88, 2012. 